\title{
Colin White, su método didáctico y la creación de la carrera de Letras Inglesas en el SUA
}

Hernán LARA ZAVALA

1

Colin White estudió literatura en Queen's College, Cambridge, donde fue discípulo del famoso profesor y crítico F. R. Leavis, de quien heredó buena parte de su peculiar estilo didáctico ["el mejor método para propiciar una discusión provechosa es ser lo más claro posible sobre lo que se ve o se juzga"], así como su gusto por los autores que Leavis clasificó como parte de "la gran tradición" de la literatura inglesa, entre los que identificaba a Charles Dickens, George Eliot, Joseph Conrad, Henry James y D. H. Lawrence. Cuando Leavis se refería a "lo más claro posible" aludía a una crítica que evitaba a toda costa aquel tipo de frases que suenan bien pero que están totalmente desprovistas de sentido y que tanto prestigio ostentan en la crítica francesa y latinoamericana. Mr. White buscaba que tanto las apreciaciones orales como escritas de sus estudiantes, ya fueran sobre una obra o un autor, se articularan con un vocabulario ceñido, directo, comprensible, pero sobre todo que evitaran todo tipo de mistificaciones, así como las jergas pseudocientíficas que estuvieron tan en boga a partir de los años setentas y por las que Mr. White siempre mostró una total y absoluta desconfianza, acaso guiado por la notoria influencia que ejerció sobre él el ensayista y también novelista E. M. Forster, miembro del Bloomsbury Group, y uno de los más destacados humanistas de Cambridge cuando él era estudiante. E. M. Forster escribió un ensayo seminal, Aspectos sobre la novela, que, aunque a muchos les parece superado por su aparente sencillez, está escrito con sentido común y la enorme sapiencia del experimentado maestro, lector y practicante del oficio de escritor que era Forster.

La otra gran influencia crítica de Mr. White era T. S. Eliot, particularmente su ensayo sobre la "disociación de la sensibilidad" ocurrida en el siglo XVII y sobre el concepto de "la tradición y el talento individual" que a él le permitió extrapolar algunas de estas ideas a otros periodos de la gran tradición de la poesía inglesa. También recurría con frecuencia Mr. White al ensayo crítico de Joyce Cary titulado Arte y realidad, y le gustaba citar un fragmento en donde Cary intenta probar que en Los hermanos Karamazov la intuición del novelista queda muy por encima de sus propias creencias religiosas, y pone como ejemplo la discusión que Iván sostiene frente a Aliosha en donde el lector se convence más de los argumentos del personaje de Iván que en los de Aliosha, que 


\section{$218 \square$ COLIN WHITE, SU MÉTODO DIDÁCTICO}

era en los que creía el escritor. Otro de sus autores favoritos y a quien leía constantemente era V. S. Naipaul. Curioso, porque su caso era exactamente el contrario al suyo. Naipaul salió de Trinidad hacia Inglaterra para encontrar su lugar en el mundo. Mr. White emprendió el trayecto inverso: salió de Inglaterra para encontrar su vocación de maestro en México. Naipaul se movió de la periferia de la civilización (Trinidad) hacia el centro, Mr. White del centro (Cambridge) a la periferia (el tercer mundo). Los que salimos ganando fuimos sus alumnos.

El método de enseñanza de Mr. White se basaba en la idea de una lectura minuciosa y lo más apegada posible al texto para su discusión en clase, en donde permitía muy pocas posibilidades a las interpretaciones "líricas" o al tipo de argumentación que suena muy elaborada pero que carece de todo trasfondo lógico y literario. Descendiente de la escuela de "Críticos de Cambridge", entre los que figuraba I. A. Richards (que por cierto tuvo como discípulos al propio F. R. Leavis y a William Empson), Mr. White nunca dejaba de lado los aspectos históricos y culturales en los que se fincaba la obra o el autor estudiado. Su primera aproximación era siempre a través de una pregunta: ¿qué piensan que quiso decir el autor con este verso? Y los alumnos aprendíamos rápido a cuidarnos de no contestar algo vago, improvisado o superficial, porque entonces $\mathrm{Mr}$. White montaba en cólera: “!¿Interesante?! ¿Qué significa 'interesante’ para usted? ¿Qué despierta su interés? ¿Su interés en qué?, a ver dígame”. Para muchos su método resultaba demasiado agresivo $\mathrm{y}$, ante el silencio generalizado del grupo frente a uno de sus cuestionamientos, le gustaba provocar, picarle la cresta a sus alumnos mediante diatribas e ironías: “¿Qué? ¿No saben pensar? ¿Están hechos de piedra? ¿Es que no han leído nada? ¿Ni siquiera Vanidades?” Algunos no resistían la presión y desertaban. Los que se quedaban, sin embargo, aprendían a contestar de manera clara, al punto, buscando el sentido de sus palabras con relación específica a la obra. Mr. White era también enemigo acérrimo de los lugares comunes, incluidos los de la alta cultura que todo el mundo asume como artículos de fe y que él se encargaba de rebatir con comentarios como el siguiente: “¿Por qué dicen que Ulises es una gran novela? Para mí es la gran carcajada de Joyce al mundo".

Sus reflexiones, siempre originales, siempre minuciosas sin llegar a ser forzadas, exageradas o sacadas de la manga, formaban parte de un método que obligaba a los alumnos a buscar la singularidad de obras y autores pero, sobre todo, a evitar simplificaciones didácticas y a rechazar los valores entendidos. Cuando empezaron a impartir clase, algunos de sus discípulos trataron de imitarlo en sus desplantes pero, como sucede con todo aquello que carece de autenticidad, se convertían en meros remedos a los que les quedaban muy grandes los zapatos de Mr. White. 
Colin White era simpatizante de la idea de que los profesores deberían poder intercambiarse asignaturas como parte de su movilidad académica y para evitar estancamientos. Con esta visión en mente, además de los tradicionales cursos de historia literaria, él impartió clases de inglés y de didáctica de la especialidad que eran parte de su fortaleza adquirida en El Anglo, así como el curso de inglés prefacultativo, materia que se les exige a aquellos alumnos que ingresan a Letras Inglesas y cuyo manejo del inglés como segunda lengua les resulta insuficiente para poder cursar las materias que se imparten en el idioma original. Para ello ideó un audaz y rápido método a partir de la lectura de poesía que permitió que los alumnos rezagados pudieran ponerse al día en sus conocimientos de inglés.

En el curso de su carrera como profesor de la Facultad, Mr. White tuvo infinidad de méritos académicos; el más importante, sin duda, haber dedicado su vida entera a formar, generación tras generación, a los estudiantes de la carrera de Letras Inglesas con toda su entrega y dedicación y sin buscar más recompensa que la de ejercer su oficio con todas las exigencias del caso. Su gran finalidad consistía en preparar a sus estudiantes para que pudieran identificar periodos y autores a partir del texto puro, mediante el reconocimiento de un tipo de lenguaje y de las imágenes afines a la sensibilidad de cada una de las épocas estudiadas. Por ello sus exámenes consistían en identificar diversos fragmentos de obras en los que el estudiante tenía que saber quién era el autor del texto para, a partir de ahí, desarrollar la idea principal y referirla al corpus general de la obra. En principio pedía que los ensayos estuvieran escritos a mano, aunque con el uso de la computadora cedió a la página impresa. Calificaba los ensayos y los devolvía tachados con comentarios feroces como "Nonsense!", "Rubbish!", "Sloppy!", "Ugly!", "Ridiculous!" El máximo comentario al que se podía aspirar como respuesta de su parte a nuestros ensayos era "Not bad". Cuando alguien le pedía una recomendación, sobre todo para hacer estudios de posgrado en Inglaterra o en algún otro país de habla inglesa, contrario a nuestras obsequiosas costumbres donde la persona que recomienda se vuelca en elogios desmesurados en favor del recomendado ("es un genio" "un estudiante único y brillante"), Colin White era de una franqueza que rozaba en el agravio con comentarios como el siguiente: "Mr. X es un estudiante más bien mediano, un tanto perezoso $\mathrm{y}$ de prosa deprimente; sin embargo, si se le estimula bien y se le presiona para que se discipline y trabaje con ahínco, podría lograr algunos resultados satisfactorios que en mucho lo beneficiarían". "Mr. White esto no es una recomendación", lo increpó uno de sus recomendados, "es casi un ataque". A lo que él respondía: "Claro que no. Lo que digo es mucho más serio que las tonterías que suele decir la gente y los dictaminadores te van a tomar más en cuenta".

Formó a varias generaciones de maestros y no hubo, entre los profesores de Letras Inglesas, quien no le debiera algo. Era un maestro a la vieja usanza: puntual, asiduo, dedicado, bien preparado, siempre vestido de corbata, preocupado por el desarrollo de sus alumnos a quienes les dirigió infinidad de tesis sobre los más diversos temas, 


\section{$220 \square$ COLIN WHITE, SU MÉTODO DIDÁCTICO}

muy formativo e, incluso, una vez que los estudiantes aceptaban sus férreas reglas, generoso, amistoso y yo añadiría que hasta afectuoso. Siguiendo una vieja tradición inglesa, solía invitar a sus discípulos más destacados a visitarlo en casa, o bien a beber una cerveza después de clase para hacer un poco de vida social y charlar sobre otros asuntos no académicos.

En la Facultad, Mr. White participó siempre, y de manera muy seria y activa, en las mesas redondas, seminarios y conferencias que se organizaban con motivo de alguna efeméride o conmemoración donde él se destacaba como excelente orador pues no le gustaba llevar nada escrito y mucho menos leer una ponencia. No improvisaba porque invariablemente daba la impresión de haber preparado bien su tema que solía iniciar bordando alrededor de dos o tres ideas que iba integrando a medida que avanzaba su charla para concluir, generalmente, con una especie de cuestionamiento más que con una aseveración. No, no fue un profesor que publicara mucho, a pesar de que a través de sus múltiples y exigentes correcciones a nuestros ensayos nos enseñó a ceñirnos en el lenguaje, a corregir eliminando frases más que añadiendo y a buscar la claridad por encima de todo rebuscamiento.

Entre los grandes méritos académicos de Colin White vale la pena destacar la fundación y diseño de la carrera de Letras Inglesas, así como la elaboración del plan de estudios de dicha carrera dentro de lo que ahora se conoce como el Sistema Universidad Abierta. Por aquellos años (¿1975-6?) fungía como coordinador del flamante Sistema de Universidad Abierta de la Facultad el doctor Óscar Zorrilla, egresado de Letras Francesas, escritor, dramaturgo, director de teatro y profesor del Colegio de Letras Modernas, y que antes había cumplido de manera excepcional con la encomienda de crear el Centro de Lenguas Extranjeras dentro de la propia Facultad, proyecto que rebasó con mucho sus alcances y dimensiones al grado de que, pocos años después de su fundación, el CELE se vio en la necesidad de mudarse a un edificio propio. Siempre afable, sonriente, inteligente y generoso, el doctor Zorrilla inició a partir de cero y con un mínimo presupuesto la planeación de un sistema paralelo al que ofrecía la Facultad en la División de Estudios Profesionales para poder atender y apoyar a los estudiantes que no contaran con el tiempo para asistir diariamente a las aulas de la Facultad. Óscar inició su proyecto nombrando a los "coordinadores" de cada una de las carreras entre los profesores que ya trabajaban en la Facultad. En Letras Inglesas eligió a Colin White.

Mr. White, individualista, empírico y pragmático como buen inglés, asumió desde el inicio una ruta absolutamente insospechada y divergente del resto de los coordinadores de las otras disciplinas del SUA y, emulando el método de tutorías que rige en las más prestigiosas universidades inglesas, y en particular en la Universidad de Cambridge, concibió una ingeniosa adaptación para que los estudiantes pudieran cursar la carrera de letras asistiendo tan solo a una tutoría una vez por semana y a un "Cursillo" un 
sábado de cada mes que, en realidad, era un ciclo de conferencias sobre diversos temas y con diferentes profesores que duraba desde las nueve de la mañana hasta las dos de la tarde. El esquema era una adaptación a la mexicana del "elitista" sistema de tutorials de Oxbridge. Antes tuvo que diseñar un plan de estudios completamente distinto al del sistema escolarizado y, con el apoyo de un grupo reducido de los que entonces éramos jóvenes profesores, Mr. White concibió, planeó, asignó y revisó las guías de estudio, la bibliografía, los materiales didácticos y las antologías que servirían de apoyo para que los estudiantes pudieran cursar su carrera sin necesidad de pisar diariamente las aulas de la Facultad.

El programa se elaboró con base en tres módulos: dado que la parte sustancial de la carrera estaba centrada en los diversos periodos que cubre el corpus de la literatura inglesa, que van de la época medieval a la contemporánea, le llamó "Módulo Principal" a las seis secciones en las que se dividieron las "historias literarias". Este módulo, apoyado por varias antologías de ensayos críticos elaborados ex profeso bajo su supervisión y abarcando cada uno de los periodos y a sus más reconocidos autores en cada uno de los géneros, permitió que los estudiantes pudieran cubrir su "lista de lecturas", previamente discutida y seleccionada, con un material didáctico que los orientara en cada curso. Las materias complementarias a la carrera, ya fueran propedéuticas, complementarias u optativas, se englobaron en lo que Mr. White llamó "Módulo Secundario", el cual incluía temas tan diversos como lingüística, filosofía, historia de la cultura, teoría literaria, lecturas de clásicos, arte, música, etcétera. El tercer módulo se denominó como de "Prácticas Acumulativas" y consistía en "ejercicios de apreciación crítica", tanto en inglés como en español, que tenían como cometido la práctica constante de la crítica a partir de poemas clásicos, lo que era una manera de ejercitar la redacción y la crítica literaria mediante breves ensayos que los estudiantes tenían que escribir semanalmente y que leían en las asesorías frente a los demás compañeros para su comentario y discusión. Durante el último semestre, los estudiantes cursaban un "seminario de tesis" sobre un autor previamente seleccionado por los integrantes de la comisión y sobre el cual cada alumno elegía algún tema que se discutía y se analizaba durante las tutorías, con la ventaja de que los pasantes culminaban sus estudios con la tesina muy avanzada. En lo particular, me tocó asesorar a una de las primeras promociones en terminar, la cual trabajó sobre el escritor inglés Henry Green, muy apreciado por Colin, y cuyas diez novelas llevan como título una o a lo mucho dos palabras a veces en gerundio (Living, Party Going, Loving, Concluding).

A falta de salones y de espacios en la Facultad para llevar a cabo las tutorías, Mr. White accedió a que los diversos grupos pudieran reunirse en casa de los asesores, creando con ello un espíritu de grupo y camaradería poco común en el sistema escolarizado. La carrera de Letras Inglesas en el Sistema Universidad Abierta ha sido un reflejo fiel de la optimización de todo tipo de recursos, desde el tiempo de estudiantes y profesores, hasta la reducción de espacios académicos y sobre todo la sustitución de la hora pizarrón por la hora de lectura e investigación, lo cual permite que los alumnos de letras se concentren sobre todo en sus bibliografías y en la elaboración de sus 
trabajos. Para los estudiantes maduros de letras, el SUA representa una opción única de concentración y esfuerzo en los estudios literarios.

La experiencia de haber trabajado bajo el mando y supervisión de Mr. White en la creación de la carrera de Letras Inglesas en el SUA significó para nosotros, sus colaboradores, tanto como haber cursado de nueva cuenta todo el currículum académico de Letras Inglesas, sólo que ahora con miras a apoyar a los estudiantes, generalmente de edad madura, a que cursaran la carrera de letras con interés, placer y toda la seriedad del caso, estimulando por igual a compañeros y tutores. Me parece que quienes participamos en este proyecto tuvimos la oportunidad única de disfrutar de una de las más ricas experiencias didácticas e intelectuales de nuestras vidas. 